\title{
Reaprendizagem de conceitos com o auxílio de recursos didáticos: experiências de formação no programa pró-letramento um relato de experiência
}

\section{Ana Maria Porto do Nascimento}

anaporto40@gmail.com

\section{Américo Junior Nunes da Silva}

amerjun2005@hotmail.com

\section{Marcos Andre Teles Luna Oliveira}

telesluna@gmail.com

\section{Adelaide Batista Corado Santos}

adecorado@hotmail.com

\section{Lidiane Carla Oliveira Franco Silva}

lidi_tea@hotmail.com

Universidade do Estado da Bahia | Brasil

\section{Resumo}

Este relato versa sobre a experiência vivenciada durante a formação de professores dos Anos Iniciais do Ensino Fundamental, na área de Matemática do Programa PróLetramento, realizado no Estado da Bahia. Os formadores articularam os saberes disciplinares e pedagógicos na busca de promover aos professores cursistas um processo de reaprendizagem significativa e o (re)pensar da prática pedagógica respeitando-se as especificidades dos educandos. A interação entre formador, orientador de estudo e professor cursista diferenciou o trabalho realizado e contribuiu na proposição de atividades de ensino que se aproximaram do trabalho em sala de aula, promovendo a (re)significação de tais atividades pelos professores para posterior utilização com os alunos. Será objeto de análise o trabalho realizado com os conteúdos de Números e Operações explorados nos fascículos 1 e 2 do Programa Pró-Letramento. Os recursos didáticos colocaram-se como instrumentos mediadores na reaprendizagem de conceitos pelos professores em formação.

\section{Palavras-chave}

Formação de Professores; Educação Matemática; Recursos didáticos. 


\section{Introdução}

A experiência aqui apresentada ocorreu na primeira etapa de formação do Programa Pró-Letramento, coordenado pela Universidade do Estado da Bahia (Uneb), Campus IX em convênio com o Ministério da Educação, com a adesão dos municípios, no ano de 2012. Este foi um programa de formação continuada de professores que buscou a melhoria da qualidade do processo de ensino-aprendizagem no país, nas áreas de Português e Matemática, nos Anos Iniciais do Ensino Fundamental. Participaram do curso: um coordenador Geral, dois coordenadores adjuntos, dois coordenadores pedagógicos, dois pesquisadores, seis formadores da área de Linguagem, seis formadores da área de Matemática e 216 orientadores de estudo. No total, foram mais de 6000 professores cursistas atendidos no estado da Bahia.

A fim de garantir a formação dos professores em exercício nos anos iniciais, cursistas do programa, foram organizados seis polos de formação, localizados em pontos extremos do Estado, sendo eles: Barreiras, Juazeiro, Guanambi, Eunápolis e Salvador. Para atender os 98 municípios da Bahia, os formadores estudaram as orientações teórico-metodológicas, contidas nos fascículos originais do programa, junto com a coordenação pedagógica e deslocaram-se do município sede até o polo em que desenvolveram as atividades com o grupo de orientadores de estudo que, por sua vez, atuaram em seus municípios como formadores dos professores cursistas.

Os formadores são estudiosos na área de Educação Matemática e isso, juntamente com o conhecimento acerca da realidade enfrentada pelos cursistas quanto ao ensino da Matemática, foi um grande diferencial para o trabalho realizado. A proposta de formação busca "desenvolver uma atitude investigativa e reflexiva, tendo em vista que a atividade profissional é um campo de produção do conhecimento, envolvendo aprendizagens que vão além da simples aplicação do que foi estudado" (BRASIL, 2007, p. 02).

Ficou evidente, durante o processo de formação, que muitos conhecimentos necessários para o ensino de Matemática nos Anos Iniciais do Ensino Fundamental não eram dominados por boa parte dos professores cursistas, o que levou-nos a repensar o processo de trabalho, considerando também a necessidade de reaprendizagem dos conteúdos pelos docentes, por acreditarmos, assim como pontua Tardif (2007), que os conhecimentos disciplinares são necessários para o exercício da docência. 


\section{Aprendizagem e construção de atividades de ensino de matemática nos} encontros de formação do Pró-Letramento

0 trabalho de formação realizado pelo Pró-Letramento foi pautado na construção de projetos de ensino, que priorizavam o processo de ensino-aprendizagem de Matemática. A utilização de materiais didáticos diversos, incluindo-se aí as ferramentas lúdicas, serviram de base para o repensar das atividades que seriam objeto de estudo durante a formação e que foram, posteriormente, realizadas em sala de aula. Acredita-se que tais atividades são importantes no processo de construção do conhecimento matemático e na desmistificação da imagem que a Matemática possui como difícil e desconectada das situações cotidianas (D’AMBRóSIO, 1996).

Destarte, nos Anos Iniciais do Ensino Fundamental também há a necessidade de estabelecer a relação entre o conteúdo matemático e alguns materiais manipuláveis (LORENZATO, 2009). 0 ensino de Matemática, como pontua Kamii (2011), precisa partir de situações concretas para situações abstratas, o que contribui, segundo Kishimoto (2009) e Fernandéz (2010) na formação de sujeitos autônomos.

Ao tratar do bloco de conteúdos Números e Operações, os PCN indicam que os números devem ser trabalhados em "situações cotidianas em que os alunos constroem hipóteses sobre o significado dos números e começam a elaborar conhecimentos sobre as escritas numéricas, de forma semelhante ao que fazem em relação à língua escrita." (BRASIL, 1997, p. 48) e "com relação às operações, o trabalho a ser realizado se concentrará na compreensão dos diferentes significados de cada uma delas, nas relações existentes entre elas e no estudo reflexivo do cálculo, contemplando diferentes tipos exato e aproximado, mental e escrito" (BRASIL, 1997, p. 35).

Esse bloco de conteúdos está contemplado nos fascículos 1 e 2 do Programa PróLetramento que serviram de referencial teórico-metodológico para esse estudo, além dos trabalhos de Muniz (2007) e Bertoni (2007) que alimentaram a formação realizada e contribuíram na ressignificação do trabalho e dos seus impactos em sala de aula.

As atividades foram discutidas nos diferentes espaços de formação: Coordenação pedagógica - Formador; Formador - Orientador de estudo e Orientador de Estudo Professor Cursista. Essa discussão era prioridade nos encontros de formação por se 
acreditar que a formação continuada precisa respeitar as especificidades dos sujeitos. Após a vivência e o ressignificar das atividades, o cursista as inseria em sua prática como exemplifica o seguinte depoimento: "Com o material concreto, meus alunos passaram a gostar mais da aula. Eu aprendi muitos conceitos matemáticos e como explorar esses conceitos com meus alunos trabalhando com o material dourado"- orientador de estudo do Município de Ibiassucê (BA).

Salientemos que isso só foi possível através do estudo dos conteúdos com o auxílio dos recursos didáticos, pois permitiu, dessa forma, a (re)aprendizagem da Matemática e sua articulação com a prática, corroborando com a fala de Menegolla e Sant'Anna (2003, p. 92- 93) que consideram que estes recursos "atuam no sentido de despertar o interesse, provocar a discussão e os debates, desencadeando perguntas e gerando novas ideias" e, de acordo com Lorenzato (2009, p. 18), esses exercícios tornam-se úteis ao processo de ensino-aprendizagem.

\section{Vivências com números e operações: a contribuição dos recursos didáticos}

Destacar-se-á nesse tópico as atividades e os recursos didáticos utilizados na exploração dos conteúdos Números e Operações, e as suas contribuições para o processo de formação de professores e sua prática, pois como bem pontuado por D’Ambrósio (1996, p. 97), é impossível pensar no professor como já formado, como aquele que não precisa aprender mais, mas é fundamental lhe oportunizar uma formação permanente. Ao realizar os encontros de formação, buscou-se, como bem colocado por Nóvoa (1997, p. 25), “estimular uma perspectiva crítico-reflexiva, que forneça aos professores os meios de um pensamento autônomo e que facilite as dinâmicas de autoformação participada".

As experiências vivenciadas envolvendo os números e as operações foram: agrupamentos e reagrupamentos com material de contagem; - operações com material dourado; - representação de números e das operações no Quadro Valor de Lugar (Q.V.L); -representação dos números com as fichas escalonadas; - construção e exploração da reta numérica (figuras 1 e 2); - a exploração de ideias associadas às operações utilizando-se o jogo de dados;- a bota de muitas léguas, entre outras.

No trabalho com agrupamentos e reagrupamentos de 10 em 10, a atividade 
desenvolvida contemplou o jogo "Nunca dez", o qual consistiu na divisão da turma de orientadores em dois grupos, denominados Equipe A e Equipe B, sendo que cada equipe, na sua vez, jogava o dado e retirava a mesma quantidade de palitos de picolé, registrando a jogada em uma tabela. Ao formar 10 unidades, deveria prendê-los com um elástico. 0 ganhador seria quem formasse primeiro um determinado número de grupos de 10 unidades, a ser determinado no início do jogo (BERTONI, 2007, p. 20).

É importante salientar que os orientadores de estudo apresentaram boa receptividade em relação a essa atividade e, ao mesmo tempo, demonstraram conceitos equivocados acerca do Sistema de Numeração Decimal, conceitos esses que foram revistos para que não houvesse reprodução de equívocos no trabalho com os alunos. A dificuldade consistia em fazer a transformação das unidades maiores em unidades menores e vice-versa. Tal dificuldade interfere diretamente na construção desse conceito, como afirma Toledo (2009, p. 58): "professores habituados a trabalhar com crianças que apresentam dificuldade em 'fazer contas' com os números naturais sabem que, na verdade, uma das principais causas do problema está no aprendizado do sistema de numeração decimal".

Foram ainda promovidas atividades com o Quadro Valor de Lugar (Q.V.L), conforme mostra a figura 4, objetivando a resolução de algumas TI'S, (Tarefas Individuais propostas nos fascículos do Pró-Letramento). Por exemplo, a TI 3 do fascículo 2 (p. 13), propõe uma subtração 208-25. Na resolução desta operação eles representaram o minuendo 208 (duzentos e oito) utilizando duas placas do material dourado correspondentes a 2 (duas) centenas e 8 cubinhos correspondendo a 8 (oito) unidades; para representar o subtraendo 25 (vinte e cinco), eles utilizaram 2 (duas) barras representando as dezenas e 5 (cinco) cubinhos representando as unidades.

Em relação à representação dos termos da subtração com o material dourado, os orientadores não demonstraram dificuldade, porém, quando foram resolver a situação proposta no enunciado da TI 3, apresentaram dificuldades em decompor uma centena em 10 dezenas, em fazer as representações e encontrar o resultado utilizando apenas o material dourado. É importante ressaltar a orientação dada pelo formador em não utilizar o algoritmo formal durante essa atividade. Outra dificuldade percebida na 
representação do minuendo 208 foi quanto à disposição das placas e dos cubinhos sem preocupar-se com o valor posicional do sistema de numeração decimal.

A partir da experiência relatada e de outras atividades desenvolvidas com o Quadro Valor de Lugar, percebe-se a validade de tal recurso para a aprendizagem dos conceitos matemáticos relacionados ao Sistema de Numeração Decimal e às operações matemáticas. Nesse sentido, o Pró-Letramento oportunizou momentos de atividades práticas e reflexão teórica sobre como trabalhar com esse recurso, pois os próprios orientadores de estudo, em sua maioria, desconheciam a utilização do Q.V.L e sua eficácia no processo ensino-aprendizagem, principalmente no que se refere aos conceitos matemáticos supracitados.

No contexto do trabalho com a subtração, a proposta desse programa de formação continuada aborda como ponto fulcral conhecer as ideias associadas a essa operação matemática que são: retirar, comparar e completar, as quais são contempladas no fascículo 2, do Pró-Letramento. Antes de resolver essas tarefas individuais, foram entregues quatro situações-problema, envolvendo a operação de subtração, a cada orientador de estudos para tentar identificar qual a ideia presente em cada situação, como previsto nos PCN. Observou-se que os orientadores não conseguiram, na grande maioria, fazer tal identificação, evidenciando-se, assim, a ausência de conhecimentos prévios referentes a esse conteúdo, pois só relacionavam a ação de subtrair com a ideia de retirar.

Outra experiência bastante significativa foi o trabalho com as fichas escalonadas uma atividade idealizada por Muniz (2007), que consiste em sobrepor uma ficha a outra com o objetivo de oportunizar ao aluno a compreensão da notação posicional dos algarismos em um determinado número. Tal recurso contribuiu positivamente para a intervenção pedagógica nos casos em que a criança, ao escrever números como 101 e 21, escreve: 1001 e 201, respectivamente, o que revela seu conhecimento a respeito da composição aditiva do número, mas demonstra que ela se esquece de suprimir os zeros.

A fim de possibilitar a vivência de uma ação associada à operação de multiplicação, foi proposta a atividade "A Bota de Muitas Léguas". Utilizando uma reta numérica que pode ser desenhada no chão e cartões numerados, a criança deve sortear um cartão cujo número indicará a quantidade de pulos que deverão ser efetuados pela 
bota imaginária. Um segundo cartão é sorteado indicando o comprimento do pulo. A turma pode ser dividida em equipes, possibilitando comparar quem calçou a bota que os levou mais longe.

A atividade também foi realizada utilizando uma folha de papel para cada aluno, que deveria representar os pulos de sua bota imaginária utilizando flechas e observando que número os pulos alcançariam. Em seguida, através da intervenção do professor, os alunos deveriam começar a observar que se 2 pulos de tamanho 3 alcançam o número 6, então 2 x 3 = 6. Essa atividade possibilitou explorar o aspecto aditivo da multiplicação por meio da reta numérica, importante recurso para o desenvolvimento do conceito não apenas da multiplicação, mas também da divisão, pois, de acordo com Mandarino (2010, p. 123), “A representação de resultados de multiplicações e divisões sobre retas desenhadas no papel pode ser usada para a observação de regularidades que ajudam a fixar a tabuada e compreender os conceitos de múltiplos e divisores de um número".

Também foi sugerido aos professores o uso de materiais de contagem como tampinhas, botões, palitos, sementes, pedras e outros materiais, como pontuam Muniz (2007) e Bertoni (2007), visando proporcionar a compreensão do sistema de numeração, bem como a vivência de atividades envolvendo as operações matemáticas.

Diante da apresentação das experiências trabalhadas neste bloco temático, percebe-se o quanto elas contribuíram para o redimensionamento e para a inovação da prática dos orientadores de estudos com seus respectivos professores cursistas, nos encontros de formação nos mais diversos municípios do estado da Bahia e, consequentemente, a sua realização em sala de aula, mostrando a importância do trabalho desenvolvido na rede de formação e no processo de ensino-aprendizagem da Matemática.

\section{Considerações finais}

A adoção de uma dinâmica de trabalho que inseriu nos encontros a manipulação de materiais didáticos, a fim de promover a reaprendizagem dos conceitos e ressignificação do ensino de Matemática parece ter provocado uma aproximação entre os professores cursistas e os professores formadores. Nesse sentido, ficou evidente que a utilização dos materiais didáticos contribuiu sobremaneira para a desconstrução de 
alguns equívocos quanto a determinados conteúdos. As atividades vivenciadas aprimoraram a prática dos professores cursistas e, consequentemente, contribuíram para a aprendizagem da Matemática e para a desmistificação da imagem que esta ainda apresentava: como difícil e desconectada das situações diárias. Isso foi possível graças ao trabalho realizado com esses materiais que tornaram as aulas mais dinâmicas e significativas e promoveram situações produtoras de conhecimento.

Em síntese, destacam-se: - os recursos didáticos colocaram-se como instrumentos na reaprendizagem de conceitos pelos professores em formação; - a dinâmica de trabalho constituiu uma rede que envolveu os formadores, os orientadores de estudo e os professores - cursistas em um processo muito produtivo de formação continuada; - o trabalho possibilitou uma reaprendizagem dos conceitos matemáticos referentes a números e operações. Essas evidências nos levam a crer que a forma como foi desenvolvido o trabalho pode ter colaborado para a efetivação de algumas mudanças, que funcionaram no sentido de indicar caminhos alternativos ao professor cursista de como realizar suas aulas de modo a promover a aprendizagem. Cientes de que inúmeros fatores interferem no bom desempenho do professor, seria ingênuo pensar que um curso, desenvolvido apenas durante um ano, possa produzir muitas mudanças, mas os resultados obtidos permitem acreditar que se houver uma continuidade e se os cursos ocorrerem numa perspectiva crítico-reflexiva, considerando, principalmente, o professor como sujeito ativo e participante de sua formação, as possibilidades de se constituir um espaço de formação continuada e colaborativa serão ampliadas.

\section{REFERÊNCIAS}

BELforT, E.; MANDARINO, M.. Programa Pró Letramento. Fascículo 2 - Números e Operações. Rio de Janeiro: Universidade Federal do Rio de Janeiro, 2007.

BERTONI, N. E.. Pedagogia: Educação e Linguagem Matemática II: Numerização. Brasília: Universidade de Brasília, 2007.

BRASIL. Secretaria de Educação Fundamental. Parâmetros Curriculares Nacionais: matemática /Secretaria de Educação Fundamental. - Brasília: MEC/SEF, 1997.

D’ AMBROSIO, U.. Educação matemática: da teoria à prática. Campinas: Papirus. 1996. 
FERNANDEZ, A.. O saber em jogo: a psicopedagogia propiciando autorias de pensamento. Porto Alegre: Artmed, 2001.

KAMII, C.. A criança e o número: implicações educacionais da teoria de Piaget para atuação com escolares de 4 a 6 anos. 39 ed. Campinas, SP: Papirus, 2011.

KISHIMOTO, T. M.. O brincar e suas teorias. São Paulo: Pioneira Thomson Learning, 1998.

LORENZATO, S. (org.). 0 laboratório de ensino de matemática na formação de professores. 2 ed. rev. Campinas, SP: Autores Associados, 2009.

MANDARINO, M. C. F.. Números e Operações - Coleção Explorando o Ensino, v. 17. Brasília, MEC: Secretaria de Educação Básica, 2010.

MENEGOLLA, M; SANT'ANNA, I.M. Por que planejar? Como Planejar? Currículo - área - aula. 13. ed. Rio de Janeiro: Vozes, 2003.

MUNIZ, C. A.. Pedagogia: Educação e linguagem matemática I. Brasília: Universidade de Brasília, 2007.

NÓVOA, A.. Formação de professores e profissão docente. In: NÓVOA, A.. (coord.). Os professores e a sua formação. 3. ed. Lisboa: Publicações Dom Quixote, 1997.

TARDIF, M.. Saberes docentes e formação profissional. 8. Ed. Petrópolis, RJ: Vozes, 2007.

TOLEDO, M.; TOLEDO, M.. Teoria e Prática de Matemática: Como dois e dois. São Paulo, FTD, 2009. 
Learning concepts with the aid of teaching resources: training experiences in the PróLetramento Program

\begin{abstract}
:
This report deals with the experience of teachers in the initial years of Elementary School in the area of Mathematics of the Pró-Letramento Program, held in the State of Bahia. The trainers articulated the disciplinary and pedagogical knowledge in the quest to promote to the teachers a process of relearning significant and (re) thinking of the pedagogical practice respecting the specificities of the students. The interaction between trainer, study supervisor and teacher differentiated the work performed and contributed to the proposition of teaching activities that approached classroom work, promoting the (re) signification of such activities by the teachers for later use with the students . The work carried out with the contents of Numbers and Operations explored in issues 1 and of the Pró-Letramento Program will be analyzed. The didactic resources were used as mediating instruments in the relearning of concepts by the teachers in formation.
\end{abstract}

Key-words: Teacher Training; Mathematical Education; Didactic resources.

\section{Aprendizaje de conceptos con la ayuda de recursos didácticos: experiencias de formación en el Programa Pró-Letramento}

Resumen: Este relato versa sobre la experiencia vivida durante la formación de profesores de los Años iniciales de la Enseñanza Fundamental, en el área de Matemáticas del Programa PróLetramento, realizado en el Estado de Bahía. Los formadores articularon los saberes disciplinares y pedagógicos en la búsqueda de promover a los profesores un proceso de reaprendizaje significativo y el (re) pensar de la práctica pedagógica respetando las especificidades de los educandos. La interacción entre formador, orientador de estudio y profesor diferenció el trabajo realizado y contribuyó en la proposición de actividades de enseñanza que se aproximaron al trabajo en el aula, promoviendo la (re) significación de tales actividades por los profesores para posterior utilización con los alumnos. Será objeto de análisis el trabajo realizado con los contenidos de Números y Operaciones explotados en los fascículos 1 y 2 del Programa Pró-Letramento. Los recursos didácticos se colocaron como instrumentos mediadores en la reaprendizaje de conceptos por los profesores en formación.

Palabras clave: Formación de profesores; Educación Matemática; Recursos didácticos.

\section{Original submetido em: 08 ago. 2017}

Aceito para publicação em: 06 dez. 2017

\section{Sobre os autores:}

\section{Ana Maria Porto Nascimento}

Professora do Centro de Ciências Exatas e Tecnologia da Universidade Federal do Oeste da Bahia (Ufob). Doutora e mestre em Educação pela Universidade de Brasília (UnB); especialista em Metodologia do Ensino Superior pela Pontifícia Universidade Católica de Minas Gerais (PUC Minas) e graduada em Matemática pelo Centro Universitário de Brasília (UniCEUB). Membro do Grupo de Estudo e Pesquisa em Matemática e Ensino de Matemática (Ufob) e do Grupo de Investigação em Educação Matemática (UnB). Atuou no Programa Proletramento como coordenadora pedagógica da área de Matemática na formação de professores do Estado da Bahia. 


\section{Américo Junior Nunes da Silva}

Professor do Departamento de Educação da Universidade do Estado da Bahia (Uneb). Doutorando em Educação pela Universidade Federal de São Carlos (UFSCar); mestre em Educação pela Universidade de Brasília (UnB); especialista em Educação Matemática e em Psicopedagogia Institucional e Clínica e licenciado em Matemática. Integra os Grupos de Estudos e Pesquisas em Educação Matemática (CNPq/UFSCar), Aprendizagem Lúdica: Pesquisas e Intervenções em Educação e Desporto (CNPq/UnB) e Formação de Professor e Currículo (CNPq/Uneb).

\section{Marcos Andre Teles Luna Oliveira}

Especialista em Educação Matemática (UNYAHNA); licenciado em Matemática (Uneb) e em Normal Superior (Uespi).

\section{Adelaide Batista Corado Santos}

Professora tutora do Programa Progestão da Secretaria Municipal de Educação de Barreiras (BA) e gestora do Brasil Alfabetizado da Secretaria Municipal de Educação de Riachão das Neves (BA). Mestre em Ciências da Educação pela Universidad Tecnológica Intercontinental (UTIC, Paraguai); especialista em Educação Matemática pelo Instituto de Educação Superior Unyahna, em Matemática Aplicada pela Faculdade Santo Antônio e em Gestão Educacional pela Faculdade Santo Antônio; licenciada em Matemática pela Universidade Estadual do Piauí, em Sociologia pela Universidade Estadual da Bahia e em Pedagogia pela Faculdade Regional de Filosofia, Ciências e Letras de Candeia.

\section{Lidiane Carla Oliveira Franco Silva}

Especialista em Ensino da Matemática pela Faculdade do Noroeste de Minas; graduada em Matemática pelo Centro Universitário Leonardo da Vinci e em Ciências Econômicas pela Universidade Estadual de Feira de Santana. Professora de Matemática no Colégio Estadual Antônio Geraldo. 